\title{
Spirituality among nursing home residents: A phenomenology of the experience of spirituality in late life
}

Spirituality can be a valuable resource for older adults, in particular to frail and vulnerable older people such as nursing home residents. The present study aimed to describe the essence of the experience of spirituality through the perspective of the nursing home residents themselves. A purposive sample of 16 nursing home residents were interviewed following Moustakas (1994) phenomenological method. Analyses of the verbalized interviews identified seven superordinate themes including 'feelings of support and trust', 'searching for meaning and finding answers', and 'a perspective beyond death'.

Keywords: spirituality; religion; meaning; nursing home; old age 


\section{Introduction}

"I have always experienced it as a final, how should I say it, a final strawlast resort for me to hold on to." 1 These are the words of a 95-year-old women describing how she experiences spirituality while facing the challenges of late life. Like many other older adults worldwide, she faces the consequences of our rising life expectancy and changed $\underline{\text { socio-culture environment, while at the same time she experiences her spirituality as a }}$ core component in her life.

The world's population is aging and virtually every country in the world is experiencing growth in the number and proportion of older persons in their population. World Health Organization (2011) stated that before 2020 the world population would be at the turning point were people aged 65 or older would outnumber the group of children under age 5. Also the number of very old or oldest old would grow significantly and would triple by 2050 . Consequently, it is expected that the population of older adults residing in nursing homes, a population characterized by its frailty and other late life challenges, will increase. Therefore, research that focusses on resourcesaspects that could be of value in dealing with the challenges of later life is important.

A potential aspect resource that might play an important role in late life is spirituality. A longitudinal study by Wink and Dillon (2002) revealed that spirituality gains in significance from late middle adulthood on. Although Dillon and Wink (2003) and later Brown, Chen, Gehlert, and Piedmont (2013) suggested that this tendency of enhanced significance of spirituality in later adulthood is most likely only partially the $\underline{\text { result of a life-cycle maturational process and likewise affected by cultural }}$ evolutions, According to Moberg (2002), argued that the increasethis tendency of enhanced significance of spirituality in later adulthood might_also be understood as a "deepening of spiritual interests and concern during the later years" (p. 15) and be related 
to the natural finitude of one's life (Johnson, 2008). Furthermore, spirituality has been found to correlate positively with late life psychological functioning (Ivtzan, Chan, Gardner, \& Prashar, 2013; Wink \& Dillon, 2003). Moreover, being spiritual turns out to be an important resource in maintaining psychological well-being, especially for vulnerable older adults such as frail, homebound, and institutionalized older adults (Fry, 2000; Han \& Richardson, 2010; Kirby, Coleman, \& Daley, 2004). Therefore, exploring these older adults' own experiences of spirituality might contribute to a better understanding of the role of spirituality in later life.

\section{Review of the literature}

As a result of the lack of consensus on its definition ${ }^{2}$, the concept of spirituality has been a hot topic for decades (see for example Cook, 2004; Tanyi, 2002). This conceptual ambiguity hampers progression in the field and limits clear communication, both within research and among practitioners (Vachon, Fillion, \& Achille, 2009). An additional challenge regarding the conceptualization of spirituality is its relatedness to religion. Although some researchers used to talk about spirituality in terms of religion and vice versa, most researchers agree that both concepts should ideally be treated as related but distinct concepts (Hill et al., 2000). In most definitions, spirituality refers to the inner subjective experience, whereas religion refers to organized faith systems (Zinnbauer et al., 1997; Zinnbauer, Pargament, \& Scott, 1999). Consequently, "adhering to a specific religion might be one of the ways to express one's spirituality" (Vachon et al., 2009, p. $53)$.

Despite the conceptual vagueness, there is considerable interest and a growing body of literature on late life spirituality. Nevertheless, only a few studies tapped directly into the experience of spirituality from the perspective of the older individual him or herself. A recent hermeneutic phenomenological study by Manning (2012) for example, 
interviewed six independent living older women aged $80+$ and found three essential themes within the experience of their spirituality: Being grateful towards the transcendent and life in general, acceptance of their late life circumstances as well as their past life, and a sense of assuredness and inner strength which arises from their spirituality. It turned out that especially the relationship with the transcendent played a central role in the experience of spirituality at an advanced age. Another interesting study by Dalby, Sperlinger, and Boddington (2012) explored whether dementia affects older adult's experience of spirituality. In-depth interviews with six adults aged 70 and older with mild to moderate dementia revealed a similar continuing relationship with the divine, regardless of the dementia. In addition, having dementia was perceived as a spiritual challenge by the participants. The older adults appraised and tried to make sense of having dementia by framing it within their spiritual beliefs. Thus, the findings of both studies seem to support the results of earlier studies and confirms literature stating that spirituality is a valuable resource for dealing with the challenges of later life (e.g., Fry, 2000; Ivtzan et al., 2013; Kirby et al., 2004).

The importance of the relationship with the transcendent in late adulthood is interesting in the light of many modern societies that are characterized by a secularization tendency. In Belgium for example, the social, cultural and political landscape was highly influenced by the Catholic church during the first half of the previous century but this gradually changed during the second half of the previous century_(Billiet, 2004; Dobbelaere, 2010; Juchtmans). Although this Catholic cultural heritage is nowadays still visible in some traditions such as the sacrament of Confirmation and the canonical wedding, and organizations such as schools, youth organizations and nursing homes which are originally based within a Catholic tradition, the Catholic faith has been mainly confined to the private realm. Only a small percentage of the Belgian population still 
identifies itself as an active adherent of Catholic faith_Bisschoppen van België,2018; Botterman \& Hooghe, 2009; Bullivant, 2018). Important to note is that this shift from a religious-framed society to a highly secularized society has taken place in the life course of these current older adults. In addition, although a substantial part of the Belgian nursing homes was established within the Catholic tradition, due to secularization and privatization religion is no longer the cornerstone of the life in, and organization of, these nursing homes. Hence, it is unclear whether and how this secularised context influences the experience of spirituality of current Belgium nursing home residents as well as how this is perceived by the older adults themselves.

Given the enhanced vulnerability of institutionalized older adults and the importance of spirituality in late adulthood, this paper presents the findings of a phenomenological study, conducted in the Flemish part of Belgium, which aimed to uncover the essence of the experience of spirituality from the perspectives of older adults living in a nursing home.

\section{Method}

\section{Participants}

Participants were selected through criterion sampling (Creswell, 2007) to ensure that participants experienced and could openly talk about the phenomenon under study. Inclusion criteria were (1) indicating that spirituality is an important part of their lifebeing spirituat, (2) being able to talk about one's experience of spirituality, (3) permanently living in a residential care setting, (4) 65 years or older, and (5) no severe cognitive, speaking and/or hearing impairment.

Sixteen nursing home residents, 6 males and 10 females, with a mean age of 86 years $(S D=5.67 \text {, range } 71-95)^{3}$ participated in the study. Nine participants considered 
themselves as Catholic, two as Christian, one as believing in a Church with a God but independent of Christian faith, and five as believing in something of which-three as believing in a transcendental reality, and one participant indicated being affiliated with Jehovah's Witnesses. Seven participants received education until 14 years of age, four until 18 years, while five participants had enjoyed higher education. The majority reported to be widowed (10 participants), three to be married and three to be single. Average time of living in the residential care setting was almost three years (range 3 months -7 year). Participants were recruited in five long-term care settings in Flanders (Belgium), two private care settings and three care settings with a Catholic background.

\section{Research design}

This study aims to gain insight and understanding into the experience of spirituality among institutionalized older adults. Moustakas' (1994) phenomenological approach which is predominantly inspired by Husserl's transcendental phenomenology was chosen as the most appropriate research approach. According to Husserl, human consciousness and the world we are living in are two aspects of the same entity which could not be studied isolated from each other (Moustakas, 1994). Investigating a phenomenon consequently necessitates capturing the way a person experiences the phenomenon, or lived experience. As the phenomenon is a product of the mind of the person who experiences the phenomenon, it can only be investigated through the first point of view of the person him or herself (Savin-Baden \& Major, 2013). Describing the lived experienced of several individuals enables researchers to grasp the essence of the phenomenon (Creswell, 2007; Eddles-Hirsch, 2015).

To uncover the essence of the phenomenon, researchers should approach the lived experience of a participant as a tabula rasa. That is, the phenomenological process of 
epoche, also known as bracketing, implies putting aside previous knowledge and perceptions of the phenomenon (Moustakas, 1994). In this case, epoche means to bracket one's own spiritual assumptions as a researcher and to transcend one's own perceptions of the phenomenon under study. Specifying one's own experience of the phenomenon prior to the study and maintaining a reflective journal during the course of the study allows the researcher to be aware of personal biases and to approach participant's descriptions of their lived experience with a more open mind.

\section{Procedure}

After gaining ethical clearance XXX ethical committee (XXX), late care residential settings in Flanders (Belgium) were contacted for collaboration. The spiritual care giver, the head nurse, or the psychologist $\theta$ f the late care settings who had the best understanding of the older adults' spiritual identity within the late care setting functioned as gatekeeper to get in touch with potential participants (Seidman, 2006). ${ }^{4}$ All information about the study was discussed individually and face-to-face with each participant by the interviewer (first author) prior to the interview and supported by an information letter for both the participants and his/her family. Informed consent was obtained at the beginning of the interview. All in-depth interviews were conducted individually in the private room of the participant, except for two participants who formed a couple and preferred to do the interview together in a double-interview. Three other participants preferred the presence of their spiritual care giver during the interview, although this person remained in the background and did not participate in the interview. All interviews were audio-recorded.

Interviews lasted between 30 and 90 minutes and proceeded until the participant indicated that there was no further information to add. The main question of the interview was: "Could you describe as detailed as possible your experience of spirituality?" 54 This question was supported with questions on feelings, thoughts, values etc. associated to 
their experience of the phenomenon. Given the close relation between the concepts of spirituality and religion as well as the interchangeable use of the words by some participants, an additional question was added for these participants to address whether they perceived these concepts as identical or different from each other. Demographic information was obtained at the end of the interview. Although no downsides caused by participating in the study were anticipated, an after care letter was provided in case participants preferred follow-up care. All participants received a voucher for two consumptions at the cafeteria of their late care residential setting.

\section{Data analysis}

$\underline{\text { To ensure consistency, aAll interviews were conducted, transcribed verbatim and }}$ analysed by the first author. Critical reflection through reflective notes and specifying the own experience of spirituality prior to the study (Creswell, 2007; Moustakas, 1994) was implemented to maximize bracketing of bias (Lincoln \& Guba, 1985). Analysis of the transcripts was conducted in line with the phenomenological methodology following the main steps outlined by Moustakas (1994). First, transcripts were read numerous times to enhance familiarity with the descriptions of each participant and to extract significant statements relative to the lived experience (horizontalization). At this stage, one participant of the double-interview was excluded for further analysis due to lack of statements regarding her lived experience that were not dominated by her partner. Next, repetitions of significant statements within a participant were eliminated and meanings were formulated for the remaining significant statements (invariant constituents). In addition, formulated meanings were clustered into themes. For each participant separately, a textural description which describes 'what' is experienced and a structural description which describes 'how' the phenomenon is experienced were formulated. 
To guarantee an accurate comprehension of participants lived experience and to maximize bracketing of bias (Lincoln \& Guba, 1985; Seidman, 2006), participants were visited a second time to present them both the textural and structural description. This process of member-checking is considered to be crucial for establishing credibility (Lincoln \& Guba, 1985). All participants agreed to member-checking, however two participants failed because of illness at the moment of the visit. Of the remaining thirteen participants, only two participants had a small clarification. Both remarks were added to their individual descriptions.

As a final step in the analysis, one exhaustive overarching description was formulated in which the different and recurring meanings derived from the individual descriptions were combined and clustered. These clusters of meanings functioned as a blueprint from which seven themes were derived which constitute the essential structure (i.e., the essence) of the phenomenon. and clusters were integrated and of which the essential structure of the phenomenon (i.e., the essence of the phenomenon) was derived.

Extensive peer discussion was integrated into different steps of the study to enhance the credibility (Lincoln \& Guba, 1985). The study design was repeatedly discussed with three colleague researchers, including the last author. In addition, the two first interviews were extensively discussed with the same three colleague researchers to optimize the interview protocol. Participants' statements which appeared as ambiguous or contradictory during the analysis were discussed with all authors, as well as the resulting themes. Lastly, member checking was discussed with the last author who also closely monitored the entire study.

\section{Findings}


Formulated meanings from all fifteen transcripts were clustered into seven themes. Although all themes and their associated subthemes will be individually discussed, one should bear in mind that the themes are not isolated from each other and that it is the unique intertwined combination of the themes that form the essence of the studied phenomenon (Moustakas, 1994), i.e., the experience of spirituality in late adulthood.

\section{Theme 1: Feelings of support and trust}

Almost all participants reported experiencing strong feelings of support and trust from their spirituality. One participant, Irène (86), described it as 'that little boost' she got that provides her the strength to face her daily hassles. Another participant, Elisabeth $(80+)^{3}$, referred to it as "a good fellow". Most participants uncovered and described the supportive side of their spirituality in the light of highly challenging life events such as the consequences of a stroke and the death of a child or partner. Statements as "it has pulled me out", "an absolute support", and "a final strawlast resort" show the significance of their spirituality and the support they derive from it during these life events.

The experience of support turns out to be inextricably linked to feelings of trust; i.e., having confidence in the availability of support when needed. This was especially true for those participants whose spirituality was inspired by the Catholic faith and who experienced a connection with a divine entity. Louisa (84) who had to recover from a stroke recalled: "The support of Our Lord helped me to heal, and because of that I gained more and more trust towards Our Lord", "I know I can trust on them [Our Lord and Mother Mary]." This experience of support and trust also encouraged participants to actively ask for support, as expressed by Liza (92) "I am in your hands God ... so teach me how to keep going" and Alfons (88) "I thank Our Lord when I had a good night and I ask him to get me through another day". 
Two subthemes emerged from this theme: feelings of gratitude and feelings of relief and tranquillity. The significance of the experienced support and trust in participant's lives is strongly reflected in participant's feelings of gratitude: "I cannot be grateful enough" and "every time again, Our Lady, thank you that I have come so far". Although most participants expressed their feelings of gratitude within the context of the experienced support, one participant, Liza (92), stated she is grateful to live and for the life she has. Experiencing spirituality as a support also appears to give rise to feelings of relief and tranquillity. As both Hubert (85) and Elisabeth (80+) explained, being able to share and entrust their concerns and struggles with the divine brings them relief and a state of tranquillity.

\section{Theme 2: searching for meaning, and finding answers}

The theme of searching for meaning and finding answers in one's spirituality is remarkable well presented by Elisabeth $(80+)$ when she recalled the period before she discovered spirituality: "I found it sad that nobody could tell me what I was supposed to do in this world and why I was here". Participants explained that they experience spirituality as something that "provides meaning to your life" and "a way of living my life". Like Elisabeth, André (80) emphasized how spirituality provides him with answers whereas "in the everyday life of eating and sleeping and whatever, answers can no longer be found". Among participants with a more religious inspired spirituality, their faith as well as religious texts turned out to be the main source from which they interpreted life and the world.

Spirituality was also referred to as "asking questions" and "having doubts" about the meaning of life and struggles one has to go through. Participants especially discussed this struggling and doubting within the context of later life. Liza (92), for example, stated "I am 92 years old and I am just good enough to sit on my couch, so what is the point". 
Another participant, Martha (88), summarized it firmly as "Why am I still here?". Annie (85), on the other hand, who lost her daughter at a young age, noted that the experience of doubts and struggles could also be a way towards finding meaning or even deeper meaning: "Sometimes you start to doubt ... but after that you become stronger again".

Two subthemes emerged from this theme: mystery and acceptance. Three of the 15 participants discussed the origin of the earth (life) which appeared to them as a mystery. Paul (71), for example, wondered "the earth did not just come into existence ... there must have been someone or something who created a neutron or proton once from which all came into being, there must be something". The mystery thus refers to what transcends the explainable and for which an answer is found within spirituality. For André (80), this entails not only the origin of earth/life but also the beauty of nature and achievements of human kind such as art and poetry. The subtheme of acceptance, on the other hand, refers to how participants find acceptance by finding meaning in spirituality; acceptance of life in general as well as acceptance of certain circumstances and events. Irène (86), for example, stated "I have prayed for it so often that, well, as a matter of fact, I understand now that I have to accept it", "accept it as God's will”.

\section{Theme 3: A perspective beyond death}

"I know there is something, but what it will look like, I don' t know", Lieske (95). The question of an afterlife is a recurrent and notable theme within the participant's descriptions. Although most participants belief in the existence of an afterlife, the precise nature of it remains enigmatic to them. Nevertheless, instead of worrying about this vague prospect, participants seem to be fulfilled with feelings of hope and reassurance: "We try to believe in it and we hope", Willy (89) and "I am not worrying", Mariette (91). For Jules (90), as well as for Pauline (89) and Mariette (94), the belief in afterlife and experiencing hope is inherently connected with being reunited with beloved ones: "I hope 
we will be reunited, but I do not know whether this will be the case because I do not know what it will be."

Although most participants reported to belief in something after death, both Paul (71) and Martha (88) explicitly stated not to believe in any afterlife. "I am not afraid to die ... because I know nothing follows afterwards, above all, I am more convinced of it since they started cremating the deceased ... in the old days, our soul went to heaven ... but now, when people are burned, nothing is left", Martha (88).

\section{Theme 4: Being a collaborator and agent of your spirituality}

Although only a few participants discussed how they perceive themselves as active collaborators of their spirituality, it is necessary to include this as a theme given its implicit presence in the descriptions of the other participants and its relevance to the overall experience. When participants talked about how they experience spirituality, it appeared as something which they have to make their own by grasping it and putting effort in it, instead of something which is given. In addition, Elisabeth (80+) remarked that you cannot force it. Putting effort in it means you let it happen, that you let the experience (spirituality) unroll itself, but in such a way that it remains "something that you construct yourself". You are "a collaborator" of your spirituality, as Liza (92) described it. This 'being a collaborator' is especially visible among participants who report a connection with a divine entity as a part of their experience of spirituality. Louisa (84), for example, stated that praying and being thankful for the support are vital parts of her spirituality because "it cannot always come from the same direction", referring that both she and the divine entity contribute to or invest in the experience.

Participants thus experienced spirituality as highly personal. In addition, participants seemed to perceive themselves first and foremost as their own agent within their spirituality. Pauline (89), for example, stated "They will not take my faith away from 
me, I have a hard time when they say something about my faith, no matter what they say." Irène (86) illustrated: "I prefer to pray focused one or two sets of ten beads instead of the whole rosary ... I am not going to do something because others say I should do so as a religious person" Although some participants described their experience, in particular the spiritual practices, by calling it "a habit" and referring to the Catholic traditions with which they have grown up, various excerpts point towards the participant being its own agent as also clarified by Alfons (88) "We are still convinced that it is as in the old days, that we have to do that, that we are obligated ... in the end, you choose yourself to comply or not".

\section{Theme 5: Beliefs}

The theme beliefs captures the cognitive frameworks underlying participant's experience of spirituality, i.e., what they believe in. Various excerpts showed that the majority of the participants believe in a connection with a divine entity. References to divine entities such as Our Lord, Mother Mary, Jesus and other faith related terms and behaviours reflect the Catholic faith inspired spirituality for all of these participants. Although most of them did not explicitly discuss the relationship with a divine entity, the reoccurrence of this theme within descriptions around other themes reflect the significance of the relationship within the experience of spirituality. For example, Hubert (85) described how he could trust his concerns and sorrows in God's hands: "In my prayer I express what is on my mind or what is bothering me ... I am happy to be able to share it with You [God]" and Pauline (89) when she recalled - quite upset - that during her holidays she was not able to visit Mother Mary because of the absence of a church or chapel in the neighbourhood: "Our Lady, I can't help it, I haven't visited you today, I wasn't able to salute you'.

Unlike the majority, one participant explained to believe in an inner strength or a spirituality which originate within the individual himself. Two other participants reported 
to believe in something. For both of them, their experience of spirituality seemed to be based on an equilibrium between the scientifically explicable and the inexplicable. One participant, however, remained unclear about the exact nature of what she believed in.

\section{Theme 6: Spiritual practices}

When participants described their experience of spirituality, they often referred to practices they regularly perform. Based on the frequency of referring, praying appeared to be the most common practice. Participants described praying as a daily and highly personal practice which enables them to communicate with the divine, i.e., asking for support and expressing gratitude for the received support. Most participants prayed in their private room, in the chapel or in another interfaith quiet room in the nursing home. Besides praying, participants also often mentioned going to/being part of religious ceremonies. Alfons (88), for example, stated "We are still participating in mass, we never skip it, it is the most important thing to me, in the time we still have left". However, for some participants, going to the chapel, following the ceremony, and praying are all closely related to each other, as illustrated by Lieske (95) her description: "Sometimes I am early [for the mass] and then I sit down in the chapel and start to pray, to Our Father ... and then a hail Mary and I include all who are present ... I always try to gather all the attending people ... if I, for example, pray the Our Father I include all people present [in her thoughts in her prayer]". Other practices mentioned by participants were meditating, reading religious and faith related texts, lighting candles, holding a cross, and singing sacred songs.

\section{Theme 7: Physical and institutional influences}

The final theme, physical and institutional influences, refers to the way participants described the experience of spirituality in the light of two interfering factors, namely their 
advanced age and current living conditions. The theme falls apart in two different subthemes: what we still can do and (in)dependency of nursing home. The advanced age of the participants appeared to have an influence on the experience of spirituality as illustrated by Willy (89), "It is different ... the way we experience our spirituality is different because we are not able anymore to do it the way we used to be". However, whereas most participants seem to have adapted without noticeable burden, some participants described it as a loss. Mariette (91), for example, who had to give up most of her Biblical reading due to too demanding, stated downhearted: "I can't exhaust myself so I had to give it all up, and that is my greatest regret."

In addition to participant's advanced age, the way participants experience spirituality seems not to be completely independent of the institutionalized context they are living in, especially with regard to the spiritual practices. Some participants, for example, complained about the liturgy in their nursing home as they are presided by lay chaplains instead of a priest, and are therefore considered to be a prayer service instead of a mass. One of the participants, Willy (89), stated not to exclude that this could contribute to a reduced experience of spirituality; "I think it will worn out, it will erode". By contrast, two other participants explicitly stated that the experience itself, regardless of the behavioural expression, is entirely unrelated to the institutionalized context.

\section{Discussion}

In this study, older adults living in a nursing home focused on their lived experience of spirituality. Phenomenological analyses of the verbalized interviews identified seven interrelated themes which as a whole form the essence of the experience of spiritualty among our nursing home residents. Consistent with existing literature (e.g., Dyson, Cobb, \& Forman, 1997; Tanyi, 2002), meaning appeared to be an important element of 
spirituality. More specific, participants descriptions about the search for meaning and how they find answers within spirituality are in line with scholars like Hill et al. (2000) and more recently Park, Edmondson, and Hale-Smith (2013) who discussed the role of spirituality in humans search or quest for meaning. Moreover, as also stressed by Park et al. (2013), excerpts indicated that participants found answers regarding both the day-today and existential aspects of life within their spirituality.

It was striking that the majority of the participants spontaneously mentioned the question of an afterlife. Although closely related to the search for meaning and finding answers, this existential question emerged as a distinct theme because of its prominent presence in the participants' descriptions. Excerpts indicated furthermore that spirituality did not provide participants with an answer, but rather functions as a framework from which they could deal with the unknown by finding meaning, and so hope and reassurance. Fortuin, Schilderman, and Venbrux (2018), for example, concluded that a strong belief system is related with lesser death anxiety among older adults, whereas Vachon et al. (2009) argued that spirituality could incite feelings of hope regarding a potential afterlife, even in the absence of specific beliefs. Vachon et al. (2009) described facing one's own approaching finitude as "part of the spiritual journey" (p. 56) in which preparing for and accepting one's death becomes the main focus during the final phase of life.

Consistent with the literature (e.g., Dyson et al., 1997), participants' spiritual beliefs, i.e., what they believed in, turned out to be another important theme which seemed to capture the cognitive framework underlying participants' experience of spirituality. Given the Catholic background of most participants, Catholic faith was an important part of the majorities experience of spirituality as, for example, reflected in the spiritual practices participants referred to as well as the repeatedly reported connection 
with a Catholic inspired divine entity. The importance of a relationship with the transcendent is a well-known and accepted element in late adulthood (Krause, 2006, 2015). Not only is it often associated with feelings of gratitude toward the divine entity (Krause, 2006; Manning, 2012), a divine relationship could also be an important source of trust and support (Coleman, 2011) as reported by most participants in the present study. Like with any significant human being, the relationship with a divine entity can be anchored in confidence and experienced as a safe haven and secure base in which the divine entity is perceived as supportive (Granqvist, 2002; Kirkpatrick, 1992). Nevertheless, both the present findings and scholars like Vachon et al. (2009) and Dyson et al. (1997) also stress the occurrence of other types of connectedness or beliefs than the belief in a divine entity.

Besides the influence of a dogmatic denomination, participants stated that spirituality is foremost a subjective, highly personal experience in which they see themselves as an active collaborator and agent, rather than a passive recipient. This is consistent with the idea that individuals experience a strong sense to be actively involved in those aspect of life which are perceived as particular significant (Thompson \& Janigian, 1988).

Lastly, although not a theme on its own, late life was clearly intertwined with the older adults' experience of spirituality. Not only was it a recurrent topic in excerpts on the search and struggle for meaning as well as in the connection with a divine entity and the perspectives beyond one's death, late life, i.e., the physical challenges related to old age and the living context of the nursing home, was explicitly noted as an interfering factor in how participants still could experience spirituality. This is in line with findings from earlier research by Coleman (see Coleman, 2011) who interviewed in the 1970s and 
$\underline{80 \text { s British older adults living in shelter homes of which several reported feelings of regret }}$ because of their inability to attend church due to age related restrictions.

\section{Reflections on the value and implication of the current study}

To ensure consistency, all interviews were conducted, transeribed verbatim and analysed by the first author. Critical reflection through reflective notes and specifying the own experience of spirituality prior to the study (Creswell, 2007; Moustakas, 1994) as well as repeated re-reading of the transcripts and the process of member checking to stay close to the participants intended meanings was implemented to maximize bracketing of bias (Lincoln \& Guba, 1985). In addition, extensive peer discussion was integrated into different steps of the study to enhance the credibility (Lincoln \& Guba, 1985): The study design was repeatedly discussed with three colleague researchers, including the last author. In addition, the two first interviews were extensively discussed with the same three colleague researchers to optimize the interview protocol. Participants' statements which appeared as ambiguous or contradictory during the analysis were discussed with all authors, as well as the resulting themes. Lastly, member checking was discussed with the last author who also closely monitored the entire study.

Although participants were recruited through purposive sampling, the resulting sample was highly religious. Not only identified the majority themselves as Catholic or Christian, participants' descriptions clearly reflected the influence of Catholic faith on the experience of spirituality. This was, however, not a complete surprise given the Catholic heritage of our Flemish (Belgium) population. Because some participants consequently used the words 'spirituality' and 'religion' interchangeable, an additional question was added to the interview protocol to ensure a correct understanding of the intended meaning of the participants: "Is religion/faith identical or different than spirituality?", and if different "What is the difference?". This procedure allowed participants to use their own 
conceptualization of spirituality. Although the religious preponderance limits the transferability of the present findings, one has to bear in mind that the aim of the current study is not to generalize but instead to become detailed descriptions of the studied phenomenon in order to come to the essence of the experience of the phenomenon.

The present findings not only synthesize the essence of the experience of spirituality among nursing home residents, they also stress the importance of spirituality for this growing group of older adults. Some purposive implications for the field can be made. First, care practitioners need to be aware of the difference between our current society and the society were the older adults have grown up in, including the spiritual and religious context. Culturally sensitive elderly care thus needs also to be attentive to the spiritual needs of the older adult, preferably by reflecting on it through the perspective of and in dialogue with the older adults themselves (see also MacKinlay, 2006). For example, in our current Flemish secularized society the mass is often replaced by a prayer service presided by a lay chaplain. Some participants complained about it and experienced it as a loss in their experience of spirituality because of the contradiction with what was told to them by the Catholic Church and the believes they hold on to for the main part of their life. Second, our findings indicated that elderly care practitioners should be attentive to older adults' the-loss experiences. More specific, changeselder adults suffer from regarding their experience of spirituality as well as a decline in the autonomy of the older adults to be their own agent of their spiritual experience can be experienced as a significant loss by the older adult. conform their own beliefs and needs. This implies that elderly practitioners who work with older adults should create space and confidentiality to discuss this. At the same time, they should be aware of assumptions regarding residents' spiritual needs which are inspired by their own spiritual needs or beliefs, instead of the needs and experiences of the residents in question (MacKinlay, 
2006). Lastly, the theme of a perspective beyond death emphasized the importance and value of integrating one's spirituality in the end-of-life care. One's spiritual beliefs may have a significant influence on the older adult's experience and perception of the approaching finitude. In addition, spirituality can be a valuable - comforting and supporting - resource to cope with this late life challenge.

In sum, by focusing on the perspective of the older adults themselves regarding the experience of spirituality in later life, this study allowed to go beyond the boundaries predefined by the present literature. That is, participants' excerpts described the experience from the older adults' point of view and shed a light on factors that affect the experience as perceived by the older adults themselves rather than what could be assumed based on the literature and earlier research. Accordingly, the present study not only contributes to the research field of spirituality and old age, but also enables researchers as well as care practitioners to transfer themselves in the shoes of spiritual older adults in order to come to a better understanding of the experience of spirituality in later life.

\section{Notes}

1. All presented quotes were translated from Dutch into English by the first author in collaboration with the third author and a bilingual person.

2. Although agreement was reached on a definition of spirituality in response to two conferences on whole-person care which focused, amongst other things, on the conceptualization problem (Creating More Compassionate Systems of Care (November 2012) 
and On Improving the Spiritual Dimension of Whole Person Care: The Transformational Role of Compassion, Love and Forgiveness in Health Care ( January 2013)) which aimed to improve the integration of spiritual care into the entire health care continuum. The following definition was proposed: "Spirituality is a dynamic and intrinsic aspect of humanity through which persons seek ultimate meaning, purpose, and transcendence, and experience relationship to self, family, others, community, society, nature, and the significant or sacred. Spirituality is expressed through beliefs, values, traditions, and practices." (Puchalski, Vitillo, Hull, \& Reller, 2014).

3. One participant refused to report her exact age, but indicated to be older than 80 years old.

4. Nursing homes decided themselves who had in-house the best understanding of the spiritual identity of their residents. The selected individuals functioned as gatekeepers who decided which residents would be eligible for participation based on, taking the inclusion criteria into account, their close relationship with the residents and their familiarity with the residents spiritual needs.

54. No additional information was given to the participants regarding the definition of the concept spirituality. 


\section{References}

Bisschoppen van België (2018). De Katholieke Kerk in België Jaarrapport 2018. Brussel: Lipac-Halewijn.

Billiet, J. (2004). Van verwerpelijke verzuiling naar geprezen middenveld: Bilan van 30 jaar onderzoek. Tijdschrift voor sociologie, 25, 129-157.

Botterman, S., \& Hooghe, M. (2009). Religieuze praktijk in België 2007: Een statistische analyse. Rapport ten behoeve van de Belgische Bisschoppenconferentie. Leuven: KU Leuven.

Brown, I. T., Chen, T., Gehlert, N. C., \& Piedmont, R. L. (2013). Age and gender effects on the Assessment of Spirituality and Religious Sentiments (ASPIRES) scale: A cross-sectional analysis. Psychology of Religion and Spirituality, 5, 90-102.

Bullivant, S. (2018). Europe's young adults and religion: Findings from the European Social Survey (2014-16) to inform the 2018 Synod of Bishops. St. Mary's University Twickenham, London: Benedict XVI Centre for Religion and Society.

Coleman, P. (2011). Belief and Ageing: Spirituality pathways in later life. Bristol: The Policy Press.

Cook, C. C. H. (2004). Addiction and spirituality. Addiction, 99, 539-551.

Creswell, J. W. (2007). Qualitative inquiry and research design: Choosing among five approaches. Thousand Oaks, California: Sage Publications.

Dalby, P., Sperlinger, D. J., \& Boddington, S. (2012). The lived experience of spirituality and dementia in older people living with mild to moderate dementia. Dementia, $11,75-94$.

Dillon, M., \& Wink. P (2003b). Religiousness and spirituality: Trajectories and vital involvement in late adulthood. In M. Dillon (Ed.), Handbook of the sociology of religion (pp. 179-). Cambridge: Cambridge University Press.

Dobbelaere, K. (2010). Religion and politics in Belgium: From an institutionalized manifest catholic to a latent Christian pillar. Politics and Religion Journal, 4, 283$\underline{296 .}$ 
Dyson, J., Cobb, M., \& Forman, D. (1997). The meaning of spirituality: A literature review. Journal of Advanced Nursing, 26, 1183-1188.

Eddles-Hirsch, K. (2015). Phenomenology and educational research. International Journal of Advanced Research, 3, 251-260.

Fortuin, N. P. M., Schilderman, J. B. A. M., \& Venbrux, E. (2018). Religion and fear of death among older Dutch adults. Journal of Religion, Spirituality \& Aging, 1-19.

Fry, P. S. (2000). Religious involvement, spirituality and personal meaning for life: Existential predictors of psychological wellbeing in community-residing and institutional care elders. Aging \& Mental Health, 4, 375-387.

Granqvist, P. (2002). Attachment and religion: An integrative developmental framework. (Doctoral dissertation). Acta universitatis upsaliensis, Uppsala. (ISBN 91-5545255-8).

Han, J., \& Richardson, V. E. (2010). The relationship between depression and loneliness among homebound older persons: does spirituality moderate this relationship? Journal of Religion \& Spirituality in Social Work: Social Thought, 29, 218-236.

Hill, P. C., Pargament, K. I., Hood, R. W., McCullough, M. E., Swyers, J. P., Larson, D. B., \& Zinnbauer, B. J. (2000). Conceptualizing religion and spirituality: Points of commonality, points of departure. Journal for the theory of social behaviour, 30, $51-77$.

Ivtzan, I., Chan, C. P. L., Gardner, H. E., \& Prashar, K. (2013). Linking religion and spirituality with psychological well-being: Examining self-actualisation, meaning in life, and personal growth initiative. Journal of religion and health, 52, 915-929.

Johnson, M. (2008). Spirituality, finitude and theories of the lifespan. In V. L. Bengtson, D. Gans, N. M. Putney \& M. Silverstein (Eds.), Handbook of theories of aging (pp. 659-674). New York: Springer Publishing Company.

Kirby, S. E., Coleman, P. G., \& Daley, D. (2004). Spirituality and well-being in frail and nonfrail older adults. The Journals of Gerontology Series B: Psychological Sciences and Social Sciences, 59, 123-129.

Kirkpatrick, L. A. (1992). An attachment-theory approach psychology of religion. The International Journal for the Psychology of Religion, 2, 3-28. 
Krause, N. (2006). Gratitude toward God, stress, and health in late life. Research on Aging, 28, 163-183.

Krause, N. (2015). Trust in God and psychological distress: Exploring variations by religious affiliation. Mental Health, Religion \& Culture, 18, 235-245.

Lincoln, Y. S., \& Guba, E. G. (1985). Naturalistic inquiry (Vol. 75). Newbury Park, California: Sage Publications.

MacKinlay, E. (2006). Spiritual care: Recognizing spiritual needs of older adults. Journal of Religion, Spirituality \& Aging, 18, 59-71.

Manning, L. K. (2012). Spirituality as a lived experience: Exploring the essence of spirituality for women in late life. The International Journal of Aging and Human Development, 75, 95-113.

Moberg, D. O. (2002). Assessing and measuring spirituality: Confronting dilemmas of universal and particular evaluative criteria. Journal of Adult Development, 9, 4760.

Moustakas, C. (1994). Phenomenological research methods. Thousand Oaks, California: Sage Publications.

Park, C. L., Edmondson, D., \& Hale-Smith, A. (2013). Why religion? Meaning as motivation. In K. I. Pargament, J. J. Exline, J. Jones, \& A. Mahoney (Eds.), APA handbook of psychology, religion and spirituality (pp. 157-171). Washington, DC: American Psychological Association.

Puchalski, C. M., Vitillo, R., Hull, S. K., \& Reller, N. (2014). Improving the spiritual dimension of whole person care: Reaching national and international consensus. Journal of palliative medicine, 17, 642-656.

Savin-Baden, M., \& Major, C. H. (2013). Qualitative research: The essential guide to theory and practice. New York: Routledge.

Seidman, I. (2006). Interviewing as qualitative research: A guide for researchers in education and the social sciences. New York: Teachers College Press.

Tanyi, R. A. (2002). Towards clarification of the meaning of spirituality. Journal of Advanced Nursing, 39, 500-509. 
Thompson, S. C., \& Janigian, A. S. (1988). Life schemes: A framework for understanding the search for meaning. Journal of social and clinical psychology, 7, 260-280.

Vachon, M., Fillion, L., \& Achille, M. (2009). A conceptual analysis of spirituality at the end of life. Journal of palliative medicine, 12, 53-59.

Wink, P., \& Dillon, M. (2002). Spiritual development across the adult life course: Findings from a longitudinal study. Journal of Adult Development, 9, 79-94.

Wink, P., \& Dillon, M. (2003). Religiousness, spirituality, and psychosocial functioning in late adulthood: Findings from a longitudinal study. Psychology and Aging, 18, 916-924.

World Health Organization. (2011). Global Health and Aging. Retrieved from https://www.who.int/ageing/publications/global_health.pdf

Zinnbauer, B. J., Pargament, K. I., Cole, B., Rye, M. S., Butter, E. M., Belavich, T. G., . . . Kadar, J. L. (1997). Religion and spirituality: Unfuzzying the fuzzy. Journal for the scientific study of religion, 36, 549-564.

Zinnbauer, B. J., Pargament, K. I., \& Scott, A. B. (1999). The emerging meanings of religiousness and spirituality: Problems and prospects. Journal of personality, 67, 889-919. 